\title{
Distal nerve transfers: a biology-based rationale
}

\author{
Justin M. Brown, M.D., ${ }^{1,2}$ Manish N. Shah, M.D., ${ }^{1}$ and Susan E. Mackinnon, M.D. ${ }^{2}$ \\ ${ }^{1}$ Department of Neurological Surgery, ${ }^{2}$ Division of Plastic and Reconstructive Surgery, Washington University \\ School of Medicine, St. Louis, Missouri
}

\begin{abstract}
Peripheral nerve injuries can result in devastating numbness and paralysis. Surgical repair strategies have historically focused on restoring the original anatomy with interposition grafts. Distal nerve transfers are becoming a more common strategy in the repair of nerve deficits as these interventions can restore function in months as opposed to more than a year with nerve grafts. The changes that take place over time in the cell body, distal nerve, and target organ after axotomy can compromise the results of traditional graft placement and may at times be better addressed with the use of distal nerve transfers. A carefully devised nerve transfer offers restoration of function with minimal (if any) detectable deficits at the donor site. A new understanding of cortical plasticity along with patient reeducation allow for good return of strength and function after nerve transfer. (DOI: 10.3171/FOC.2009.26.2.E12)
\end{abstract}

$\begin{array}{lll}\text { KEY WORDS } & \bullet & \text { brachial plexus injury } \quad \bullet \quad \text { distal nerve transfer } \\ \text { nerve graft } & \bullet & \text { plasticity }\end{array}$

$\mathrm{D}$ ISTAL nerve transfers require the cutting of healthy nerves subserving one function and suturing of these proximal donors to selected branches within a region of denervation to restore a specific motor or sensory function. ${ }^{20}$ Lurje $^{19}$ was an early pioneer in the use of nerve transfers to treat Erb palsy, and since that time such techniques have been widely used as the intervention of choice in cases of nerve root avulsion. Over the last decade, a plethora of new nerve transfer procedures has been added to the repertoire of the peripheral nerve surgeon.$^{35,37}$ In fact, functional restoration has undergone a paradigm shift with increasing acceptance of distal nerve transfers as a viable alternative to proximal nerve reconstruction. ${ }^{3,20}$ What previously took a year or more to accomplish with variable results can now be reliably accomplished in months with such transfers. The success of these interventions is multifactorial and results from more timely reinnervation, selective sensory versus motor nerve donation, and fresh axotomy of the donor nerve. In the present study we review the basic science behind the benefits of distal nerve transfers and the theoretical basis for why these procedures have found their place in reconstruction after peripheral nerve injuries.

Abbreviations used in this paper: $\mathrm{AIN}=$ anterior interosseous nerve; FCR = flexor carpi radialis.

\section{Challenges to Successful Reinnervation After Nerve Injury}

It is well accepted that prolonged axotomy affects axonal regeneration deleteriously. Axonal regeneration is known to occur at only $\sim 1 \mathrm{~mm}$ per day. This timing accounts only for the arrival of the first axons, with full recovery some time later. In proximal injuries regeneration can often take longer than 2 years, severely limiting the results of such repairs. ${ }^{12}$ The delay between axotomy and reinnervation is one of the most important limiting factors to the success of peripheral nerve repair. Axotomy-related changes occur within the cell body, distal nerve stump, and target end organ, all of which are known to compromise the success of functional recovery (Fig. 1). ${ }^{8,11}$

After 6-18 months of denervation, the target muscle is frequently not restored to full strength even when an appropriate complement of axons is provided. ${ }^{34} \mathrm{~A}$ denervated muscle atrophies rapidly, losing $>60 \%$ of its mass and $90 \%$ of its maximum force within a month of axonal deprivation. Prolonged axonal deprivation of muscle fibers can result in their inability to recover fully from denervation atrophy. ${ }^{4,10}$ Although the authors of many reviews on the subject of peripheral nerve repair refer to the degeneration of motor end plates, the decline in the ability of denervated muscle to accept axons is more likely to be due to other causes. The loss of myonuclei followed by 
J. M. Brown, M. N. Shah, and S. E. Mackinnon

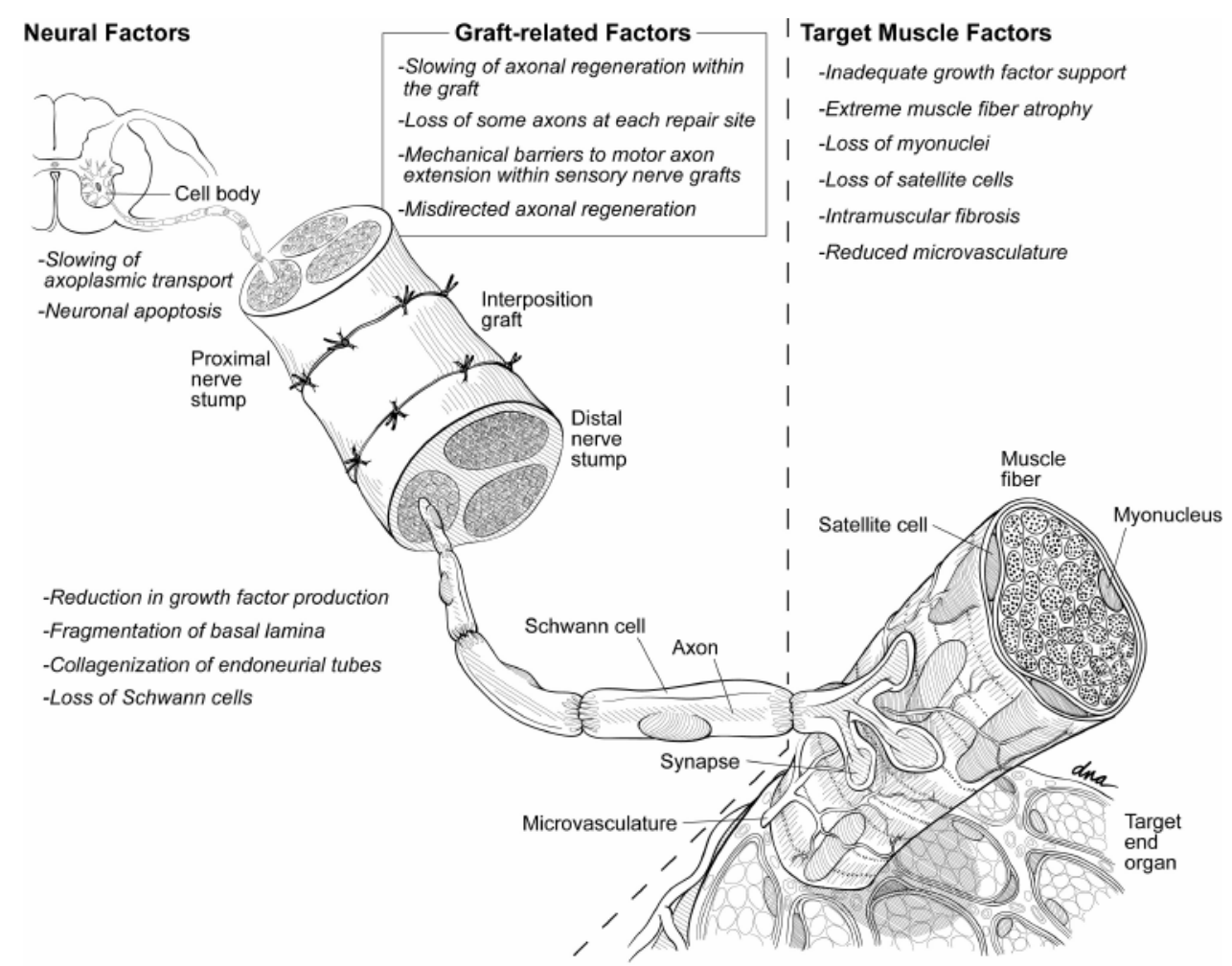

FIG. 1. Illustration showing various axotomy-related changes that are deleterious to axon regeneration (prepared by DNA Illustrations, Inc., www.dnaillustrations.com).

loss of muscle fibers, exhaustion of satellite cell regeneration, drop in capillary density, and fibrosis appear to be the most critical contributors to this loss of receptivity. ${ }^{2,4}$

Despite this reduced regenerative capacity, axonal sprouting is preserved in the fibers that do successfully reinnervate muscle. This collateral sprouting is the basis for motor unit compensation in the target muscles, and involves expansion in motor unit size in the remaining healthy motoneurons. This expansion can be quite robust, allowing for a 3- to 5-fold increase over the original motor unit size. ${ }^{12}$

Sensory recovery is likewise adversely affected by prolonged denervation, although to a much lesser extent. Pacinian corpuscles, more so than other mechanoreceptors, can fibrose over time, limiting their receptivity to reinnervation. Meissner corpuscles, Merkel cells, and Ruffini endings are better able to retain their receptivity to reinnervation. ${ }^{23,38}$

Although much attention has been focused on the reduced ability of the chronically denervated muscle to accept axons, it has been proposed that the distal nerve stumps actually account for more of the progressive failure of axonal regeneration. ${ }^{30}$ After axotomy Wallerian degeneration takes place, degrading axons and myelin debris are cleared, Schwann cells proliferate and line up to form the bands of Bungner, and their phenotype is changed to "growth support" mode. The Schwann cells provide crucial basement membrane proteins, cellular adhesion molecules, and neurotrophic molecules that both promote and direct the regeneration of axons. ${ }^{8}$

The distal nerve stumps thus initially provide a favor- able environment for the elongation and guidance of axons to their targets. Over time, however, denervated Schwann cells may undergo apoptosis, and those that survive become less supportive due to diminishing production of these factors. Fragmentation of the Schwann cell basal lamina and collagenization of endoneural tubes imposes an additional mechanical barrier to successful axonal extension. ${ }^{2}$ Chronic denervation thus compromises the formerly permissive environment for regenerating axons.

Successful axon elongation is also dependent on the survival of the axotomized neurons and their ability to extend axons effectively. Similar to the Schwann cells in the distal nerve, these neurons must convert from transmitting mode to growth mode through various gene regulatory changes. ${ }^{8}$ Retrograde cell death of both motor and sensory neurons is known to occur after axotomy. The effects on motoneurons of retrograde cell death secondary to axotomy are related to the age of the patient, the proximity of the axotomy to the cell body, and the time from axotomy to repair. ${ }^{15}$ This cell death among the dorsal root ganglion neurons, which preferentially affects cutaneous afferents, is more robust and appears to be less dependent on the distance from the cell body. In addition, this sensory cell loss also occurs in a delayed fashion so that immediate repair minimizes this effect. ${ }^{9}$

Of the surviving neurons, the number that effectively extend axons and make connections with muscle fibers or sensory receptors are significantly reduced after prolonged axotomy. Axonal regeneration is directly limited by the slow axonal transport rate which is known to degrade over time. ${ }^{12}$ This rate of degeneration has been found 

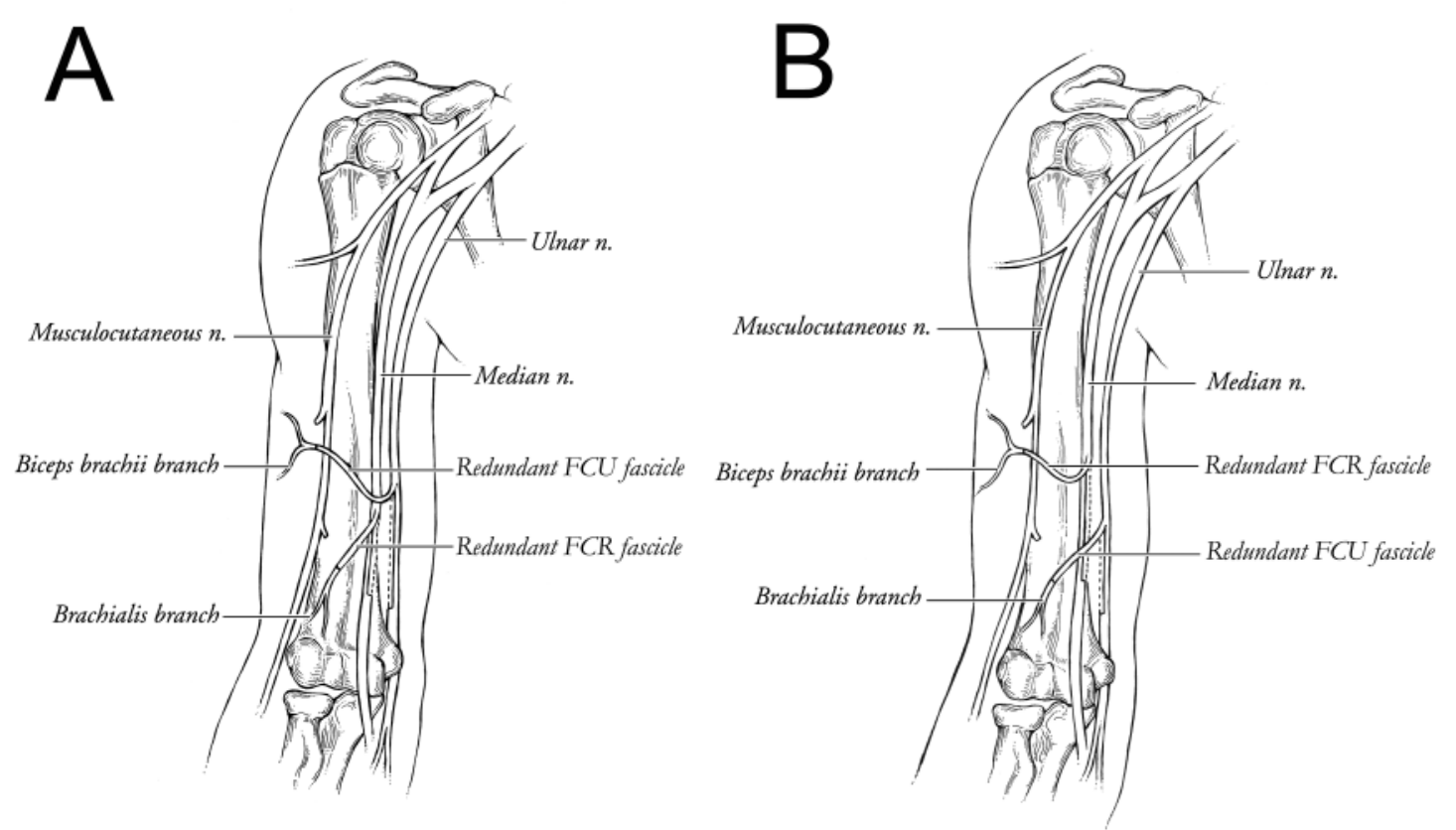

FIG. 2. Illustration depicting 2 approaches to restoration of elbow flexion using nearby fascicles of the median and ulnar nerves, which are transferred directly to branches to the biceps brachii and brachialis muscles within centimeters of their motor end plate. A: A fascicle of the ulnar nerve with flexor carpi ulnaris (FCU) function has been transferred to the biceps brachii branch and a fascicle of the median nerve with flexor carpi radialis (FCR) function has been transferred to the ulnar nerve. B: The FCR has been transferred to the biceps brachii and the FCU to the brachialis. $n=$ nerve. Adapted from J Am Society Surgery Hand, Vol 4. Weber RV, Mackinnon SE. Nerve transfers in the upper extremity. pp 200-213, 2004, with permission from Elsevier.

to occur in an exponential fashion (with a time constant of 40 days) and is reflected in the reduction in response to trophic factors at the level of the cell body. ${ }^{9}$ In Fu and Gordon's study, ${ }^{9}$ delayed nerve repair of $>6$ months after axotomy reduced the number of regenerating motor neuron axons to one third of the original number. Therefore, the ability of the surviving neurons to effectively extend axons is progressively impaired with time.

Apart from the challenges afforded by the various aspects of the motor or sensory neuron from soma to target end-organ, traditional nerve grafting presents other obstacles to successful functional recovery. Grafts, for example, do not provide an optimal environment for nerve regeneration. In fact, slowing of regeneration compared to native nerve in long grafts has been demonstrated. ${ }^{36}$ This effect is multifactorial and partly attributable both to the requirement for nutrient diffusion (in a nonvascularized graft) and the possible structural factors involved in motor axons traversing a sensory graft..$^{16,26}$ In addition, repair sites are known to interfere with regeneration. Regenerating axons take tortuous paths across suture sites, some even making retrograde turns back into the donor nerve trunk. ${ }^{12}$ Repairs have been shown to produce some degree of fibrosis. ${ }^{7}$ An interposition nerve graft requires 2 separate repairs, multiplying these effects. ${ }^{21,25}$ Scar tissue formation at the distal suture site has been observed, and this can additionally impede regenerating axon sprouts. ${ }^{25}$ Anatomical repairs are frequently compromised by the presence of both motor and sensory fascicles in the proximal nerve that are not well delineated. Both fiber types can therefore enter the graft and the resulting aberrant regeneration reduces the number of functional synapses that result. ${ }^{25}$ Finally, the harvesting of the nerve grafts, such as the frequently used sural nerve, leads to sensory deficits and, occasionally, pain. ${ }^{24}$

\section{Advantages of Nerve Transfers}

Nerve transfers were once considered salvage procedures whose only role was providing axons when the original source was unavailable, such as in root avulsion injuries. ${ }^{6}$ Nerve transfers have since been found in many clinical settings to provide a more robust result than the original axon source; the reasons for this relate to the discussion above. ${ }^{20}$

The use of an axon donor close to the target structure can reduce denervation time substantially. As a result, the changes related to distal nerve sheath and end organ degeneration can be minimized. ${ }^{14}$ Nerve transfers involve the recruitment of a previously uninjured nerve for the provision of axons, usually near its target..$^{27}$ As a result, the trigger in motor neurons to undergo apoptosis is minimized, and the cell bodies of these newly recruited axons have had little or no time to undergo apoptosis given the immediate suture repair. The apoptosis that might have been triggered in the sensory afferent cells in the dorsal root ganglion is likewise minimized because of the immediate repair. ${ }^{15}$ In addition, the transformation of the donor neuronal machinery to "regeneration mode" is initiated at the time of the intervention. ${ }^{8}$ The slow axonal transport is therefore moving at its optimal pace. Each of these factors promotes a more robust recovery. 
J. M. Brown, M. N. Shah, and S. E. Mackinnon

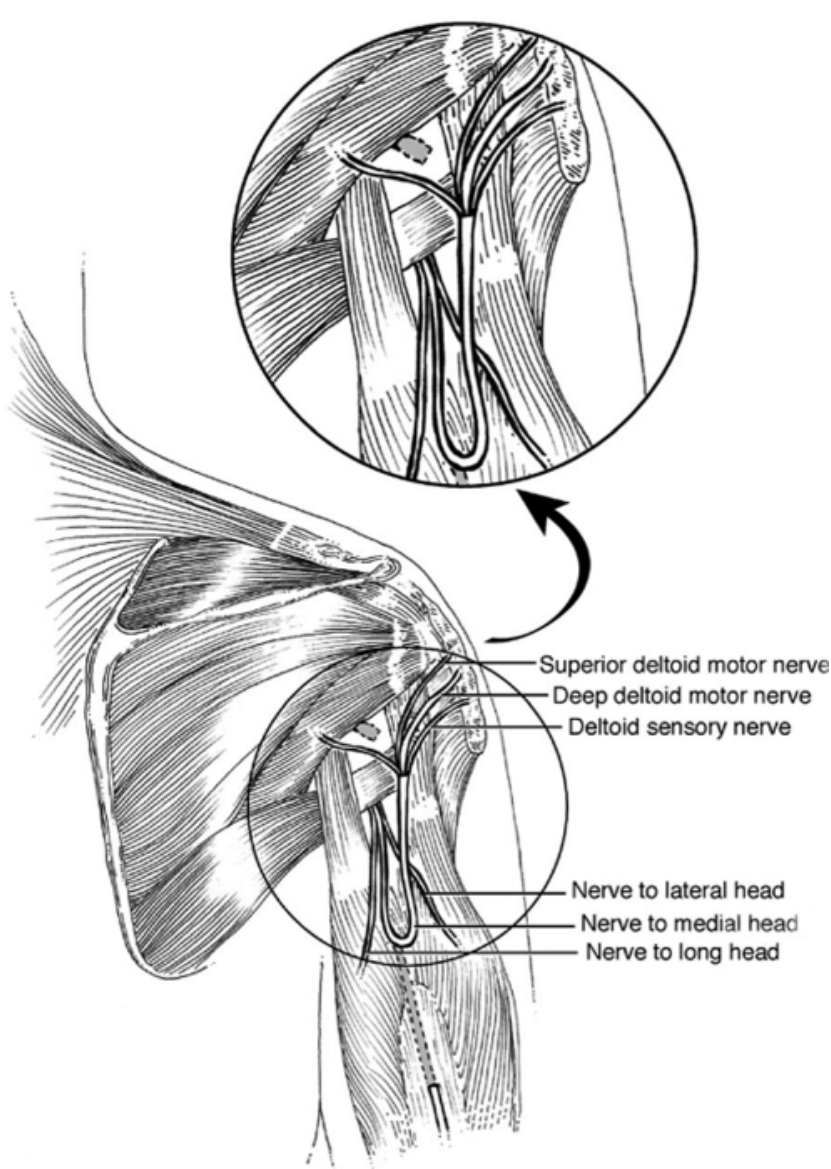

FIG. 3. Illustration showing the authors' variation on the transfer introduced by Leechavengvongs. In this distal transfer, the longer branch of the radial nerve to the medial head of the triceps is cut and transferred to the axillary nerve for restoration of shoulder function. $\mathrm{m}=$ muscle. Adapted from Operative Tech Orthopaedics, Vol 14. Tung TH, Weber RV, Mackinnon SE. Nerve transfers for the upper and lower extremities. pp 213-222, 2004, with permission from Elsevier.2004, with permission from Elsevier.

When nerve transfers are used, in most cases the need for interposition grafts is eliminated. This obviates the requirement for a second coaptation, minimizing the loss of axons that occurs to some degree at each repair site. In addition, the decrement in axonal transmission and slowing of that transmission, which has been found to occur in even autologous nerve grafts is eliminated. Finally, recruiting distal donors allows for the selection of pure motor and sensory axon sources, removing the possibility of sensory-motor aberrancy in neurotization.

\section{Successful Distal Nerve Transfers}

As mentioned in the introduction, there have been many attempts at restoring distal brachial plexus function using nerve transfers and proximal grafting. ${ }^{19,32}$ The pitfalls of more proximal grafting are that fewer axons effectively innervate their target end organs because of the distance of axon growth and the multifunctionality of the transfer nerve with the variable motor and sensory fascicular topography. ${ }^{6}$ Distal nerve transfers address these

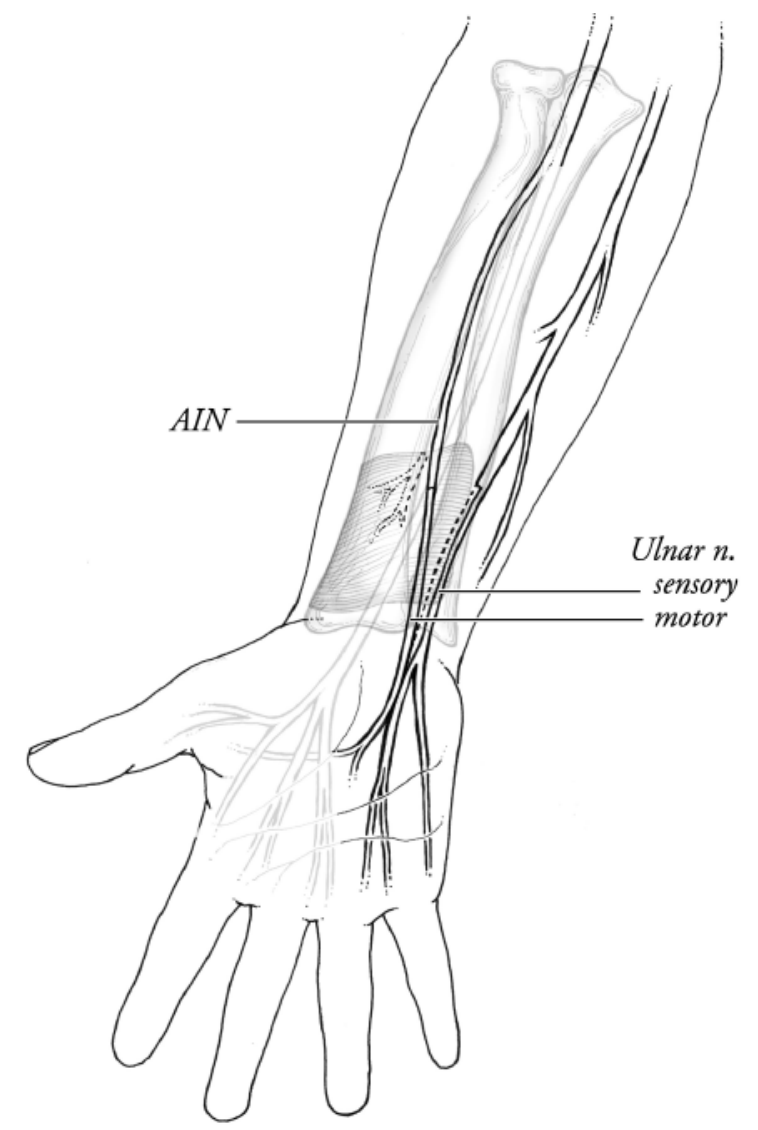

FIG. 4. Depiction of the distal transfer strategy for the restoration of ulnar intrinsic function by transferring the distal aspect of the anterior interosseous nerve from within the pronator quadratus to the deep ulnar motor branch. Adapted from J Am Society Surgery Hand, Vol 4. Weber RV, Mackinnon SE. Nerve transfers in the upper extremity. pp 200-213, 2004, with permission from Elsevier.

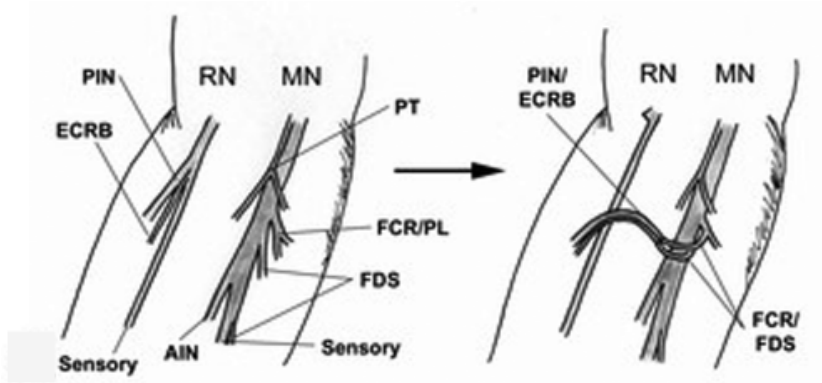

FIG. 5. Illustration of a volar forearm approach that exposes branches of the median and radial nerves. The median nerve-radial nerve transfer for restoration of wrist and finger extension is depicted. Using the radial nerve branch to the extensor carpi radialis brevis (ECRB), transfers to the median nerve can also be accomplished. Restoration of pronation is accomplished by transfer to the nerve to the pronator teres. Likewise, restoration of finger flexion is effected by transfer to the anterior interosseous nerve. Radial nerve (RN) branches include the posterior interosseous nerve (PIN) and nerve to the ECRB. Median nerve (MN) branches include the anterior interosseous nerve (AIN), nerve to the pronator teres (PT), nerve to the FCR and palmaris longus (FCR/ $\mathrm{PL}$ ), and nerve to the flexor digitorum superficialis (FDS). Adapted from Hand Clin, Vol 24. Brown JM, Mackinnon SE. Nerve transfers in the forearm and hand. pp 319-340, 2008, with permission from Elsevier. 


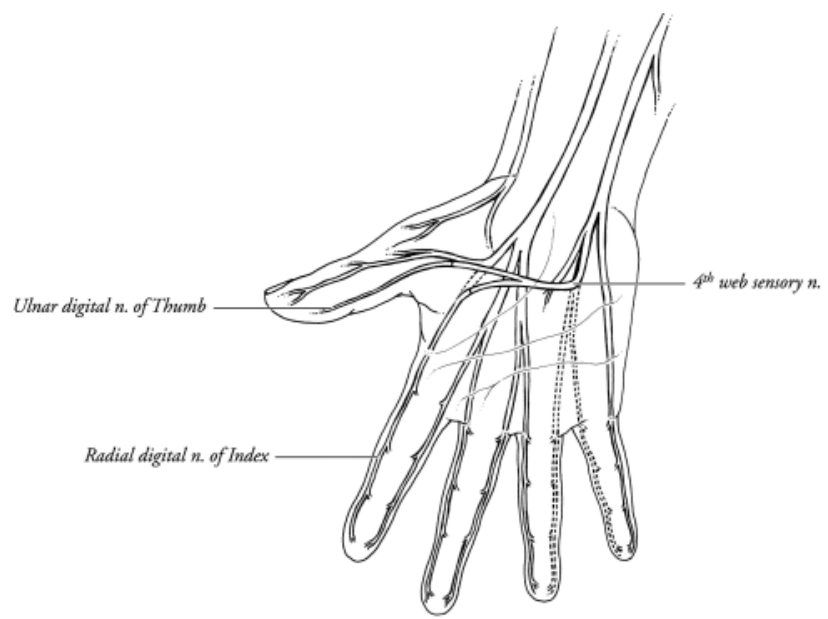

FIG. 6. Drawing showing transfer of the branch of the ulnar nerve that provides sensation to the 4th web space to the median innervated 1 st web space in a proximal median nerve injury. The sensation is provided to the ulnar aspect of the thumb and the radial aspect of the index finger as depicted. Adapted from J Am Society Surgery Hand, Vol 4. Weber RV, Mackinnon SE. Nerve transfers in the upper extremity. pp 200-213, 2004, with permission from Elsevier.

obstacles by grafting to more oligo- or monofunctional nerve branches at a short distance from the target organ.

Oberlin's transfer of a fascicle of the ulnar nerve directly to the branch of the musculocutaneous nerve innervating the biceps brachii for the restoration of elbow flexion marked the beginning of the transition toward increased use of distal nerve transfers. ${ }^{29}$ This intervention alone provided for M4 muscle strength (Medical Research Council scale) in early series. ${ }^{18}$ The addition of a graft from a fascicle of the median nerve to the branch of the musculocutaneous nerve innervating the brachialis muscle quickly made this a very robust intervention, matching, if not exceeding, the results achieved in most cases of anatomical nerve repair (Fig. 2). ${ }^{22}$ This concept has since been effectively applied to the restoration of shoulder function as well. In the traditional procedure, the distal spinal accessory nerve branch is transferred to the suprascapular nerve along with grafting to the axillary from either proximal elements of the plexus or medial pectoral nerve branches. The replacement of the latter intervention with transfer of adjacent branches of the radial nerve that innervate the triceps muscle has had a similar impact. The transfer of triceps branches to the axillary nerve, thereby avoiding the use of interposition grafts, has provided much better shoulder recovery in these injuries. In our modification, the longer branch of the radial nerve to the medial head of the triceps is used because it is easier to mobilize than the traditionally used branch to the lateral head (Fig. 3). ${ }^{5,17}$ Application of these concepts to individual nerve injuries beyond the brachial plexus has allowed the restoration of ulnar intrinsic function, which was rarely recovered in proximal grafting. This result was accomplished with a simple transfer of the distal AIN from within the pronator quadratus to the
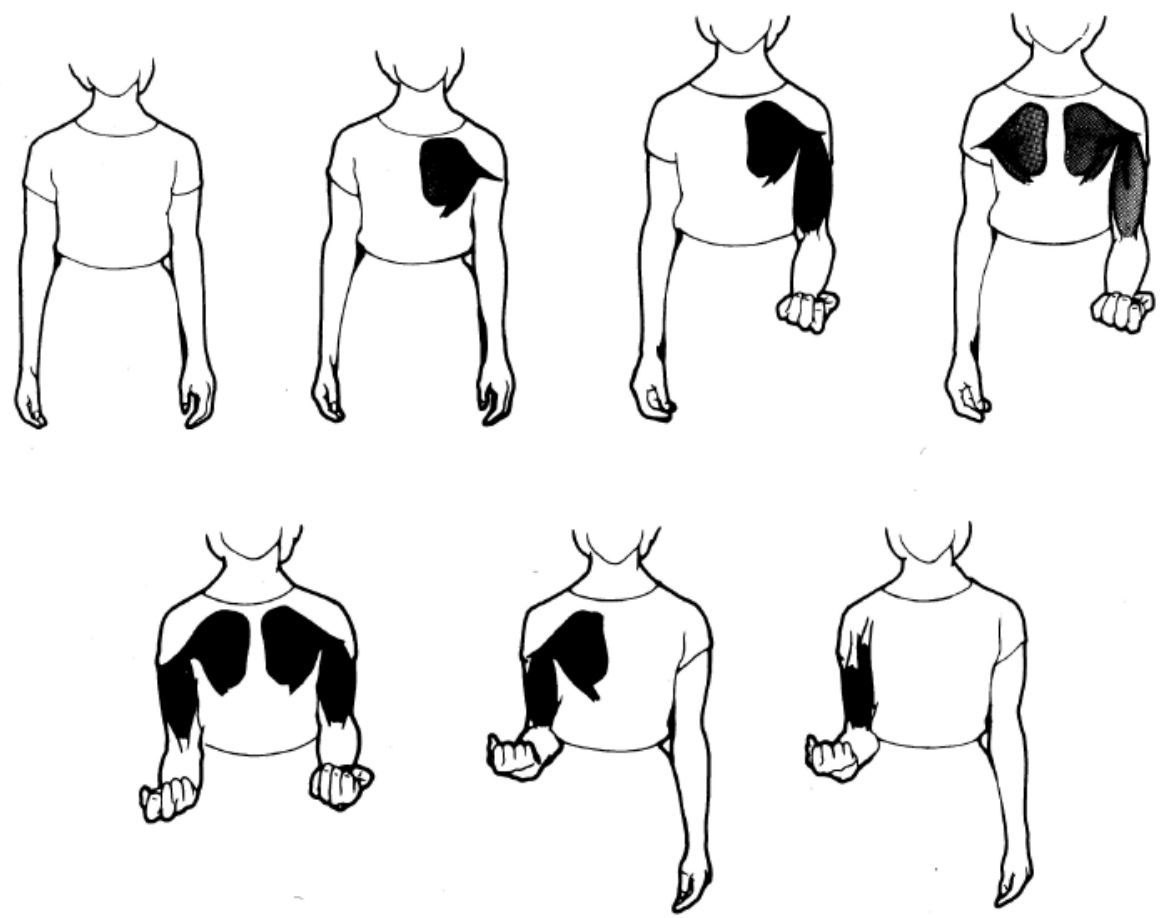

FIG. 7. Diagram illustrating the reeducation process after a nerve transfer for restoration of musculocutaneous nerve function from the medial pectoralis nerve. First, the patient is taught to recruit the contralateral pectoralis muscle followed by the contralateral biceps to develop awareness of how to selectively recruit these muscle groups. Next, the patient transfers this skill to the affected side. Finally, the donor pectoralis and reinnervated biceps are recruited in concert until the patient learns to discriminate these functions. Soon he will learn to activate independently the reinnervated muscle alone without "tricks." This same concept can be applied to other nerve transfers. Adapted from Hand Clin, Vol 15. Mackinnon SE, Novak CB. Nerve transfers. New options for reconstruction following nerve injury. pp 643-66, 1999, with permission from Elsevier. 
deep motor branch of the ulnar nerve (Fig. 4). ${ }^{28}$ Multiple permutations of nerve branch transfers between the median and radial nerves within a single volar forearm incision have provided for effective restoration of pronation, finger and wrist extension, and finger flexion. Specifically illustrated are the coaptations of the median nerve branches that innervate the flexor digitorum superficialis and the FCR muscles to the radial nerve branches to the posterior interosseous nerve and the nerve to the extensor carpi radialis brevis muscle, restoring finger and wrist extension (Fig. 5). From the same approach, a deficit in the AIN providing finger flexion can be addressed via a transfer from the radial nerve branch to the extensor carpi radialis brevis. Likewise, this radial nerve branch can be transferred to the pronator teres nerve branch in cases of isolated loss of pronation. ${ }^{13}$ Sensory transfers have also been found to be effective. ${ }^{3}$ Transfer of the branch of the ulnar nerve that provides sensation to the fourth web space to restore median sensation to the first webspace in a proximal median nerve injury can provide useful sensation relatively rapidly (Fig. 6). ${ }^{3}$ Utilization of the common digital branch of the median nerve to the third web space to directly restore sensation to the first webspace in an upper plexus injury has also been demonstrated to be safe and effective. ${ }^{20}$ Similar use of this branch to restore sensation to the ulnar distribution of the hand is beneficial. Such transfers continue to be added to the literature and are being applied to a variety of neurological deficits.

\section{Concerns With Nerve Transfers}

Many peripheral nerve surgeons are concerned with the difficulties of motor or sensory reeducation and the possibility of creating a new deficit with sacrifice of the donor nerves. Transfers have been devised to capitalize on the redundancy of the nervous system by the recruitment of otherwise trivial functions. Although there are reports of functional consequences with the use of some donors, such as the distal spinal accessory, most transfers represent carefully devised exchanges in which the sacrifice of the function of 1 distribution is more than compensated for by the function achieved as a result. Fascicular transfers, such as the "double fascicular" for elbow flexion, capitalize on proximal redundancy and in most cases do not result in a discernible deficit. In the double fascicular transfer, fascicles from the median and ulnar nerves that normally contribute to the innervation of the FCR and the flexor carpi ulnaris muscles, respectively, are directly transferred to the biceps and brachialis branches of the musculocutaneous nerve to restore elbow flexion (Fig. 2). ${ }^{31}$

One of the greatest concerns of physicians has been the ability of the patient to relearn functions that are now driven by disparate motor pools. Clinically we have not found this to be a substantial problem. Many transfers, in fact, are adopted spontaneously with little or no training. Malessy et al. ${ }^{1}$ have carefully demonstrated the cortical plasticity that occurs in the supplementary motor cortex. These changes mimic the acquisition of a new skill. An increase in excitability and decrease in intracortical inhibition represents "priming" which takes place at the onset of learning. The area of cortical representation enlarges initially and then decreases as the skill is mastered. In keeping with this, practice is invaluable in reinforcing the new cortical connections. Learning to recruit the donor muscle groups preoperatively is helpful, as is continuously repeating these activities until reinnervation is recognized. Then early activation of the motor movement with gravity eliminated should be encouraged. This ideally is followed by strengthening and endurance exercises over the next year or so. Such a regimen will ensure the most robust results (Fig. 7). ${ }^{1}$

\section{Conclusions}

In their review of outcomes following nerve grafting, Vanderhooft and Allan ${ }^{33}$ conclude, in keeping with our discussion above, that "gaps greater than $5 \mathrm{~cm}$, age greater than 20 years and nature of injury (blunt versus sharp) adversely affects outcome." In their conclusion they assert that "surgeons must strive to recognize and modify factors that affect patient outcomes." We believe that the appropriate utilization of distal nerve transfers accomplishes just that.

\section{References}

1. Anastakis DJ, Malessy MJ, Chen R, Davis KD, Mikulis DJ: Cortical plasticity following nerve transfer in the upper extremity. Hand Clin 24:425-444, 2008

2. Bain JR, Veltri KL, Chamberlain D, Fahnestock M: Improved functional recovery of denervated skeletal muscle after temporary sensory nerve innervation. Neuroscience 103:503510,2001

3. Brown JM, Mackinnon SE: Nerve transfers in the forearm and hand. Hand Clin 24:319-340, 2008

4. Carlson BM, Borisov AB, Dedkov EI, Dow D, Kostrominova TY: The biology and restorative capacity of long-term denervated skeletal Muscle. Basic Appl Myol 12:247-254, 2002

5. Colbert SH, Mackinnon SE: Posterior approach for double nerve transfer for restoration of shoulder function in upper brachial plexus palsy. Hand 1:71-77, 2006

6. Dvali L, Mackinnon S: Nerve repair, grafting, and nerve transfers. Clin Plast Surg 30:203-221, 2003

7. Eren F, Yuksel F, Ulkur E, Cavdar S, Ercan F, Celikoz B: Nerve regeneration through a healthy nerve trunk: a new and hopeful conduit for bridging nerve defects. Plast Reconstr Surg 116:1697-1705, 2005

8. Fu SY, Gordon T: The cellular and molecular basis of peripheral nerve regeneration. Mol Neurobiol 14:67-116, 1997

9. Fu SY, Gordon T: Contributing factors to poor functional recovery after delayed nerve repair: prolonged axotomy. J Neurosci 15:3876-3885, 1995

10. Fu SY, Gordon T: Contributing factors to poor functional recovery after delayed nerve repair: prolonged denervation. J Neurosci 15:3886-3895, 1995

11. Furey MJ, Midha R, Xu QG, Belkas J, Gordon T: Prolonged target deprivation reduces the capacity of injured motoneurons to regenerate. Neurosurgery 60:723-733, 2007

12. Gordon T, Sulaiman O, Boyd JG: Experimental strategies to promote functional recovery after peripheral nerve injuries. J Peripher Nerv Syst 8:236-250, 2003

13. Hsiao EC, Fox IK, Tung TH, Mackinnon SE: Motor nerve transfers to restore extrinsic median nerve function: case report. Hand (N Y) [epub ahead of print], 2008

14. Humphreys DB, Mackinnon SE: Nerve transfers. Oper Tech Plastic Reconstruct Surg 9:89-99, 2003 


\section{Distal nerve transfers: a biology-based rationale}

15. Jivan S, Novikova LN, Wiberg M, Novikov LN: The effects of delayed nerve repair on neuronal survival and axonal regeneration after seventh cervical spinal nerve axotomy in adult rats. Exp Brain Res 170:245-254, 2006

16. Kanaya F, Firrell J, Tsai TM, Breidenbach WC: Functional results of vascularized versus nonvascularized nerve grafting. Plast Reconstr Surg 89:924-930, 1992

17. Leechavengvongs S, Witoonchart $\mathrm{K}$, Uerpairojkit $\mathrm{C}$, Thuvasethakul P: Nerve transfer to deltoid muscle using the nerve to the long head of the triceps, part II: a report of 7 cases. $\mathbf{J}$ Hand Surg [Am] 28:633-638, 2003

18. Leechavengvongs S, Witoonchart K, Uerpairojkit C, Thuvasethakul P, Ketmalasiri W: Nerve transfer to biceps muscle using a part of the ulnar nerve in brachial plexus injury (upper arm type): a report of 32 cases. J Hand Surg [Am] 23:711716, 1998

19. Lurje A: Concerning surgical treatment of traumatic injury of the upper division of the brachial plexus (Erb's type). Ann Surg 127:317-326, 1948

20. Mackinnon SE, Colbert SH: Nerve transfers in the hand and upper extremity surgery. Tech Hand Up Extrem Surg 12:2033,2008

21. Mackinnon SE, Nakao Y: Repair and reconstruction of peripheral nerve injuries. J Orthop Sci 2:357-365, 1997

22. Mackinnon SE, Novak CB, Myckatyn TM, Tung TH: Results of reinnervation of the biceps and brachialis muscles with a double fascicular transfer for elbow flexion. J Hand Surg [Am] 30:978-985, 2005

23. Maggi SP, Lowe JB III, Mackinnon SE: Pathophysiology of nerve injury. Clin Plast Surg 30:109-126, 2003

24. Matsuyama T, Mackay M, Midha R: Peripheral nerve repair and grafting techniques: a review. Neurol Med Chir (Tokyo) 40:187-199, 2000

25. Meek MF, Coert JH: Clinical use of nerve conduits in peripheral-nerve repair: review of the literature. J Reconstr Microsurg 18:97-109, 2002

26. Moradzadeh A, Borschel GH, Luciano JP, Whitlock EL, Hayashi A, Hunter DA, et al: The impact of motor and sensory nerve architecture on nerve regeneration. Exp Neurol 212:370-376, 2008

27. Nath RK, Mackinnon SE, Shenaq SM: New nerve transfers following peripheral nerve injuries. Oper Tech Plastic Reconstruct Surg 4:2-11, 1997
28. Novak CB, Mackinnon SE: Distal anterior interosseous nerve transfer to the deep motor branch of the ulnar nerve for reconstruction of high ulnar nerve injuries. J Reconstr Microsurg 18:459-464, 2002

29. Oberlin C, Beal D, Leechavengvongs S, Salon A, Dauge MC, Sarcy JJ: Nerve transfer to biceps muscle using a part of ulnar nerve for C5-C6 avulsion of the brachial plexus: anatomical study and report of four cases. J Hand Surg [Am] 19:232237, 1994

30. Sulaiman OA, Gordon T: Effects of short- and long-term Schwann cell denervation on peripheral nerve regeneration, myelination, and size. Glia 32:234-246, 2000

31. Tung TH, Novak CB, Mackinnon SE: Nerve transfers to the biceps and brachialis branches to improve elbow flexion strength after brachial plexus injuries. J Neurosurg 98:313318,2003

32. Tuttle HK: Exposure of the brachial plexus with nerve transplantation. JAMA 61:15-17, 1913

33. Vanderhooft E, Allan $\mathrm{CH}$ : Functional outcomes after nerve grafting. Atlas Hand Clin 10:93-99, 2005

34. Viguie CA, Lu DX, Huang SK, Rengen H, Carlson BM: Quantitative study of the effects of long-term denervation on the extensor digitorum longus muscle of the rat. Anat Rec 248:346-354, 1997

35. Weber RV, Mackinnon SE: Upper extremity nerve transfers, in Slutsky DJ, Hentz, VR (eds): Peripheral Nerve Surgery: Practical Applications in the Upper Extremity. Philadelphia: Churchill Livingstone Elsevier, 2006, pp 89-108

36. Wong AY, Scott JJ: Functional recovery following direct or graft repair of nerve gaps in the rat. Exp Neurol 114:364366,1991

37. Wood MB, Murray PM: Heterotopic nerve transfers: recent trends with expanding indication. J Hand Surg [Am] 32:397-408, 2007

38. Zelena J: Survival of Pacinian corpuscles after denervation in adult rats. Cell Tissue Res 224:673-683, 1982

Manuscript submitted October 15, 2008.

Accepted November 25, 2008.

Address correspondence to: Justin M. Brown, M.D., Department of Neurological Surgery, 660 South Euclid Avenue, Washington University, St. Louis, Missouri 63110. email: brownjm@nsurg. 